\title{
A Patient Education and Counseling Prospectus on Substance Use and Infectious Disease Risk Reduction Programming for Men Exiting Prison
}

\author{
Torrance Stephens* and Aniya Allen \\ Department of Psychology, Clark Atlanta University, USA
}

Submission: February 01, 2017; Published: February 17, 2017

*Corresponding author: Torrance Stephens, Department of Psychology, Clark Atlanta University, USA, Email: tstephensphd@gmail.com

\begin{abstract}
During the 70's, 80's, and 90's, the United States raced to incarcerate more people than any other nation in the world. The imprisonment and reentry system is in need of major reform. Imprisoned men and women have high rates of chronic illnesses, infectious diseases, and substance abuse disorders. The major infectious diseases include Human immunodeficiency virus/ acquired immune deficiency syndrome (HIV/AIDS), Hepatitis B and C, and Tuberculosis (TB), all of which can be transferred to other inmates, and to un-incarcerated communities upon prisoner release. Severe alcohol/drug abuse, inconsistent access to HIV and other prevention and education services, and lack of peer-led and culturally sensitive interventions contribute to the high rates of disease seen in incarcerated populations. Based on a peer education model, the authors outline a substance use and infectious disease risk reduction program for men exiting prison, with the following overarching goals: to develop an eight session, six month intervention that will preserve the health status of releasees, reduce activities that promote the spread of infectious diseases in the outside community, prevent parole revocation or other recidivism, and improve the community response to inmates leaving prison.
\end{abstract}

Abbreviations: HIV: Human Immunodeficiency Virus; AIDS: Acquired Immune Deficiency Syndrome; TB: Tuberculosis; ID: Injection Drug; IDU: Injection Drug Use; NIDA: National Institute of Drug Abuse; ATOD: Alcohol, Tobacco, and Other Drug

\section{Introduction}

At the end of 2015, there were more than 6.7 million persons under the control of the U.S. criminal justice system [1]. Of this number, approximately 600,000 to 688,000 individuals annually are released from U.S. state and federal prisons who return to their communities [2,3]. Prisoner reintegration is very problematic given that having spent longer terms behind bars many are not prepared for life on the outside of being incarcerated and often display difficulties obtaining and sustaining employment and even reconnecting with their families when they return. Moreover, inmates leaving correctional systems may be impacted by substance abuse and health problems [4-8].

For many, they may be rearrested and return to prison for new crimes or parole violations. National statistics note that prison inmates are nearly six times more likely than the general population to have the Human Immunodeficiency Virus (HIV) [9]. The CDC has noted that in the state of Georgia that the estimated prevalence of HIV infection is nearly five times higher for incarcerated populations $(2.0 \%)$ than for the general US population [10]. This is compounded by institutional policies designating condoms as contraband. This is a major problem since primary risk factors for HIV are having unprotected sex and having sex with multiple partners. Also, other identified risk factors, such as injection drug use (IDU), needle sharing and tattooing, are indisputably prevalent in prisons and jails regardless of prohibitions against these activities [11,12].

High-risk activities are very widespread among the incarcerated (up to one-third of inmates report having sex with other men and up to one-half report IDU) [13-15] some have indicated that there are more injection drug (ID) users in correctional facilities than there are in drug treatment centers $[16,17]$. Although the first major risk factor identified for AIDS was unprotected anal sex, IDU has always been the most predominant among the incarcerated because inmate populations are drawn heavily from the IDU population outside of prison [18]. 
The purpose of this article is to provide an overview of programmatic efforts that can be implemented to provide health education to correctional populations. Specifically as it relates to substance use and infectious disease risk reduction. The intervention is designed to target inmates prior to being released from prison and incorporates substantial community followup with peer social support. The rationale for the proposed approach is that following release from prison, inmates are moved directly from a very controlled environment to a low level of supervision or complete freedom. Prisoners, during this juncture, often report feeling anxious about re-establishing family ties, finding employment, and managing finances once they return to their communities [19].

\section{Justification for targeted substance use and infectious disease prevention for former inmates.}

Sexual transmitted infections (STIs) such as HIV is passed between persons primarily through specific sexual and drugusing behaviors, namely unprotected sex and IV-drug use. Since there is no vaccine to prevent HIV transmission, efforts to prevent such transmission must rely heavily on interventions that can reduce risky behaviors associated with risky sexual practices and substance use. Targeting relatively homogeneous groups such as inmates returning to their community allows for tailoring of activities to address specific needs and risk behaviors that are common among group members given that both infectious disease risk and recidivism for inmates are related to ineffective transitioning of inmates back to community life.

Structural impediments including but not limited to lack of job opportunities, underemployment, unemployment, lack of marketable skills, racism, classism, poor housing, and a constrained opportunity structure serve as antecedent factors in a vicious cycle that relegates social offenders to a permanently marginalized status and as barriers to re-entry. Barriers involving inadequate access to health and social services, lack of knowledge of the correctional system and client referral sources, lack of discharge planning prior to release, lack of job training opportunities, negative attitudes, and communication difficulties exacerbate the plight of the parolee's stabilization and social reintegration to community life. Thus, managing reentry to achieve long-term reintegration to have far-reaching benefits for the families and communities most affected by reentry, as well as for former prisoners.

\section{Objectives}

The objectives of the patient education model are multi-fold and are listed as follows:

1) To provide patient education professionals working with correctional populations the knowledge to develop and implement sexual health and substance use reduction programming for men out of prison ;

2) to discuss ways to change attitudes and beliefs of inmates related to re-integration into the community at large;

3) to develop a sustainable, cost-effective intervention for health programming for men out of prison that would preserve health status of releasees when returning to the community;

4) to reduce activities that promote the spread of STIs in the un-incarcerated communities;

5) to prevent parole revocation or other recidivism; and

6) to encourage the practice of health efficacious behaviors that both reduce the chances of contracting infectious disease, STIs, substance use and recidivism.

\section{Theoretical framework}

The theoretical framework behind the proposed intervention is based on Social Cognitive Theory and problem behavior theory. These principles recognize that instructional information alone is often insufficient for motivating people to change their behavior. Moreover, in concert with an extensive communityfollow-up component, such an intervention has a greater chance to impact behavioral change that can serve to reduce the chances of contracting and spreading infectious disease as well as reduce the likelihood of returning back to prison.

\section{Social cognitive theory}

Social Cognitive Theory and its principles for behavioral change are especially important for encouraging specific behaviors such as condom use. Social Cognitive Theory emphasize factors associated with self-efficacy specifically as related to using condoms (e.g., mechanical ability to use condoms, social ability to encourage condom use by one's partner) as well as the perceived outcomes or consequences of using condoms [20,21]. By concentrating on a specific health behavior, interventions that incorporate social cognitive principles are often successful in promoting that behavior across different situations. A major tenet of the Social Cognitive Theory is that behavior is dynamic and depends on characteristics of the individual as well as his/ her environment [22].

\section{Problem behavior theory}

Problem Behavior Theory recognizes that behaviors such as delinquency, risky sex, and substance use tend to cluster among high-risk individuals and also attributes these behaviors to an underlying disposition toward social deviance. Problem Behavior Theory holds that the disposition for social deviance is associated with specific psychosocial risk factors, including poor self-esteem, low motivation for achievement in traditional domains (e.g., school, organized sports), unsupportive family relationships, and a deprived neighborhood [23,24].

\section{Community Engagement and Collaboration}

Successful interventions with inmate populations require cooperation with local and state agencies as well as affiliates of public health services. This includes local and state departments 
of health, and state board of pardons and paroles. Parole is the discretionary decision of the state board of pardons and paroles to release a certain offender from confinement after he or she has served an appropriate portion of a prison sentence. Persons on parole remain under state supervision and control according to conditions which, if violated, make way for reimprisonment.

Standard conditions which apply to all parolees include: following all instructions from the parole officer, working gainfully, abiding by all laws, remaining in the state, receiving permission to change address, paying any court-ordered child support, paying a parole supervision fee, and (if applicable) paying restitution. Parolees may not own or use a gun or other deadly weapons. Protection of the public and the successful reintegration of the offender back into the community are the hallmarks of parole supervision. The goal is to carefully transition the offender back into the community and to quickly re-incarcerate those offenders who choose to disregard the conditions of parole.

\section{Methods}

In the 2003-2004 year, the authors were in the final phases of a National Institute of Drug Abuse (NIDA) grant funded to implement Infectious disease risk reduction and general health self efficacy to a sample of soon to be released adult male inmates in Georgia, United Sates. The intervention was based on a peer education model in which patient education materials were presented by former inmates who were either HIV positive or HIV negative [25]. The intervention program was designed to reduce risky sexual behaviors, alcohol, tobacco, and other drug (ATOD)-related behaviors once the felon returns to the community. A pool of eligible participants was selected by department of correction personnel. To be eligible for inclusion, inmates had to be between 60 and 90 days prior to release from the facility, and returning to the metropolitan Atlanta area (this criterion would make follow-up more feasible). Inmates had to be 18 years of age or older, male, and sexually active.

\section{Demographics of Georgia Inmate Population}

The total Georgia prison population as of May 2006 was 51,653 , with more than 140,000 on probation and 23,142 parolees. Approximately $94 \%$ male and $67 \%$ non-white inmates. Inmates age 22-39 years account for $63 \%$ of the population. The mean age of inmates is 33.8 years. Diagnostic behaviors reports indicated that $3 \%$ of the state inmate population has escape tendencies, $20 \%$ assaultive tendencies, $18 \%$ an alcohol problem, and 38\% a drug problem. The average length of sentence (excluding life and death sentences) is 11.12 years and the average (including life and death sentences) is 12.37 years (http://www.dcor.state.ga.us/)

\section{Intervention}

Behavioral sciences and correctional policymakers have long known about the critical period that makes inmates returning to the community vulnerable to social forces that negatively impact their adjustment to community living. During the first 72 hours following their release from correctional facilities, these inmates are confronted with a myriad of challenges that can potentially become self-defeating if poor choices are made. As has been mentioned, former drug using inmates are likely to fall prey to the same environmental forces that led to their incarceration when they are returned to those same community settings. The desire for female companionship, and specifically sexual encounters, is typically high on their list of first activities upon release. Unprotected sex is potentially a dangerous engagement that can result in contracting numerous infectious diseases including STIs.

Secondly, these inmates may fall prey to the use of illegal controlled substances during their first few days in transition. During the first 72-hours after release and after participating in the peer led intervention while incarcerated, project staff intensely monitor, motivate, counsel, and assist these men as they transition back into their home communities through referrals and connecting them with needed human support services. From this perspective, the "moment of release" presents opportunities for policy innovation and attention- to develop strategies that build a short-term bridge during this immediate transition period. Currently, released prisoners encounter few resources to help them secure employment, access substanceabuse treatment, and reestablish family and community ties. The combination of these pre-release preparations coupled with follow-up on the outside (via parole, interviewers, peer educators, nonprofit community organizations, faith institutions, family or friends) might reduce the risk of recidivism or drug relapse and improve the odds of successful reintegration after release.

Newly-released (former drug users) male ex-offenders will typically seek illegal drugs and female companionship soon after release. During this early post release period, they seek intimacy from significant others, prostitutes or young females. Unprotected and risky sexual behavior (RSB) is typical during the first week upon release. Moreover, as noted above, newly released male inmates 30 years of age and older are likely to be anxious to engage in sexual intercourse, and are more likely to dismiss the importance of safer sexual practices. For all of these factors, newly released inmates are likely to occupy a compromised position as it relates to health beliefs and health practices.

Client advocacy, mental health counseling, access to employability skill development programs, and peer support groups are all critical areas for socializing and habilitating the newly released inmate to the values of the dominant society. These transitional dynamics need to be addressed through the development of interventions, which are culturally competent, gender specific, and responsive to parolees receiving educational services, substance abuse treatment and prevention services, job training opportunities, and safe, affordable housing options. 
Responsive discharge planning is also a key element. Maximizing the extent of articulation between the prison staff and the parole officers can only increase the effectiveness of the overall system from continuity of care perspective.

Intervention components: A male peer educator will meet with all participants in group meeting three weeks prior to being released into the community. In this curriculum, each session builds on the one before, so that the content of early sessions is reinforced by the content of later sessions. The Peer educators will address the topics listed in the twelve sessions below.

\section{Session 1:}

Introduction: The health educator will provide an overview of the intervention. He will discuss the importance of a future goal orientation, especially in relation to family and community involvement. The participant will be asked to generate an action plan, which includes a short list of immediate goals, with an emphasis on risky sex behaviors, ATOD use, and recidivism.

\section{Session 2:}

Coping Strategies, including Stress Management: The health educator will present effective coping strategies, including ways to manage stress. He will discuss life stressors, including interpersonal conflicts in the home and on the job, domestic violence, and the use and abuse of ATODs. The need to be responsible toward oneself and others will be emphasized and further illustrated with examples of positive consequences of being responsible (e.g., stable relationships, steady income, private property) and negative consequence of being irresponsible (e.g., lack of significant relationships, job loss, ill health, poor self image). Strategies for handling stress will be identified.

\section{Session 3:}

STI, HIV, and AIDS Education: The health educator will provide information about STIs, HIV, and AIDS. This will include the signs and symptoms of STIs, HIV, and AIDS and transmission of these diseases. He will also discuss the role of ATODs in RSBs.

\section{Session 4:}

STIs and HIV Prevention: The health educator will present strategies for avoiding STIs and HIV, with an emphasis on the use of condoms. Specific attention will be given to attitudes toward condoms held by the participants' peers, potential partners, and society as a whole. The health educator will utilize a factual and non-confrontational approach to restructure negative attitudes that participants hold toward condoms.

\section{Session 5:}

Alcohol and Tobacco Education: The health educator will provide demographic information about the use of alcohol and tobacco and its impact on health and well being. The health educator will provide demographic information about the use of illegal substances and its impact on health and well being.

\section{Session 6:}

Dietary Behavior, Physical Activity and Cancer Risk: Peer Educators will provide parents with a series of educational tip sheets on family diet. This information will also target the importance of physical activity and reduced sedentary behavior as well as risk from common cancers, methods of detection and general information specific to these cancers, specifically, prostate, colorectal and lung cancers.

\section{Session 7:}

Family/ Community Reintegration: The Peer educator will provide practical tips on searching for appropriate job training programs and/or jobs. He will also give useful strategies to follow in obtaining job interviews, including punctuality, appearance, manners, verbal and nonverbal cues, and appropriate questions to ask. The health educator will emphasize the need for participants to get their families involved during their habilitation process and also, building social supports. A list of community resources, including the types of services that each agency or organization provides, will be given to each participant. For those offenders who are interested in receiving educational degrees, they will be given pertinent information and application materials.

\section{Session 8:}

Wrap-up: The health educator will return to the topic of the need for long-term personal goals, especially in relation to family and community involvement. Emphasis will be placed on providing information about support systems and obtaining information about the "significant others" that they anticipate having in their environment upon their release. This contact will also introduce a number of venues that will be available to assist them in their adjustment to community living.

Additional focus will be placed on issues of supervision and appropriate interactions to stay within the guidelines of parole. The transition facilitator will make use of the existing institutional pre-release plan and augment this plan as appropriate and in consultation with parole officials to:

a. maintain proper communication with the parole officer,

b. adhere to all guidelines pertinent to supervised parole, and

c. for those on electronic monitoring, reinforcement of the rules relative to monitoring compliance.

These sessions will be delivered between 6:30 and 8:00 PM. This is generally free time at many state prisons. The decision to deliver the sessions at this time was based on the advice of state corrections officials who indicated that minimal disruption 


\section{Global Journal of Addiction \& Rehabilitation Medicine}

in the existing schedule would ensure more support for the intervention from the prison staff.

Day of release: The day of their release, the inmate will be met "at the gate" by program staff. These staff will accompany the releasee and/or meet him at his place of residence. At that time, the staff will also meet the family and/or residence members and work to strategize with the releasees and their families and/ or significant others about the releasees activities for the next three days. Community linkages will already be underway. The releasees will be trained on the use of the cell phone and how to maintain contact with project staff, their parole obligations, potential employment opportunities, and other important facets of their transition.

Next Four Days: The next four days will consist of daily phone contacts by the program staff. In addition, the participant will be introduced to their assigned peer educator. At this time, the peer educator will evaluate the substance abuse discharge plan and make recommendations and referrals to community-sponsored treatment meetings (Alcoholics Anonymous, Narcotics Anonymous, Cocaine Anonymous, Emotions Anonymous) based on the participant's needs assessment. The peer educator will conduct a behavior intervention response plan primarily based on the one-on-one consultation. The participant will maintain regular contact with the peer educator via telephone as well as through face-to-face encounters during this four day period.

Next Three Weeks: Progress will be monitored by the staff in all critical areas of the participant's reintegration into the community and family. During this period, staff will collect and maintain all records pertaining to participant's ability to keep scheduled appointments (parole meetings, medical appointments, recovery group meetings, and job interviews). Staff will also record participant's ability to secure an identification card, a driver's license, social security cards, etc. When necessary, the interviewer and PE will assist the releasee by shadowing him and providing some transportation to appointments.

Months Three and Four: Months three and four staff will collect and assess written and oral feedback from the participants as well as community service providers, employers, and family members. This information will be used to adjust the service plan and determine short term goals for the participant. Services will be added or deleted based on needs assessment. The participants will play a major role in formulating ongoing services to be implemented.

Months Five and Six: The staff will begin the phasing out stage with the participant. During this period, the staff will make weekly calls to each participant to obtain current status profiles and progress reports. A participant summation report will be requested from all community agencies involved in treatment plan. The contents of these summary reports, as well as the total phase out, will be discussed with each participant during the exit interview.

\section{Discussion}

This paper proposes a standard approach for patient education programs for soon-to-be released inmate populations for the purpose of Infectious disease risk reduction and reduced recidivism. It is presented in such a manner that it may be successfully disseminated at both the state and federal level. The limited research that has been conducted concludes that heightened stress levels documented at the time of release reflect very real anxieties about successfully managing a return to the outside world for former inmates [26-29]. Previous studies support the notion that released offenders tend to employ ineffective coping styles in an attempt to deal with everyday problems [30,31].

In addition to dealing with problem behaviors associated with being incarcerated, substance use and infectious disease risk reduction interventions that target inmates returning to the community should include services that builds on education in the facility, and will aid former inmates in using the prevention strategies they learn as they encounter risk situations outside of prison [32-34]. Tracking is essential and interventions need to consider providing participants with disposable cell phones within the first 72 hours of their release from prison. [35] Doing such will provide program participants with the ability to both send and receive calls. The issue of prisoner reintegration is taking on new importance as more prisoners are retuning home. The cycle of removal and return of large numbers of men in urban communities exasperates the already enormous social and economic disadvantages these communities encounter.

\section{Conclusion}

This intervention framework is a multifaceted and comprehensive program that not only places special emphasis on reducing substance use and HIV risk reduction, but also focuses on activities that will assist former inmates after they return to their communities. This program purports that aftercare and booster services are especially important for former inmates because after they are released they may be immediately exposed to a high-risk environment: places, persons, or situations - and few have developed relapse prevention skills during their incarceration to deal with these risks. Health promotion efforts focused on soon-to-be-released inmates implemented in correctional settings based on peer and self-help models will foster and support the development and practice of selfprotective behaviors that will aid in infectious disease risk reduction. The strategies in this prospectus include both preand post-release support for incarcerated individuals that will successfully reintegrate them back into their communities as well as improve the health and safety of their communities. It is a thorough and realistic scheme for addressing this population's risks. 


\section{Global Journal of Addiction \& Rehabilitation Medicine}

\section{References}

1. Kaeble D, Glaze L, Tsoutis A, Minton T (2016) Correctional Populations in the United States, 2014. Bureau of Justice Statistics, Washington DC, USA.

2. Beck AJ (2000) State and federal prisoners returning to the community: Findings from the Bureau of Justice Statistics. In First Reentry Courts Initiative Cluster Meeting, Washington, DC, USA.

3. Wagner P, Sakala L (2014) Mass incarceration: the whole pie. Prison Policy Initiative, Northampton, MA, USA.

4. Braithwaite R, Stephens T, Conerly RC, Jacob Arriola K, Robillard A (2004) The relationship among marijuana use, prior incarceration, and inmates' self-reported HIV/AIDS risk behaviors. Addict Behav 29(5): 995-999.

5. Spaulding AC, Clarke JG, Jongco AM, Flanigan TP (2009) Small reservoirs: Jail screening for gonorrhea and chlamydia in low prevalence areas. J Correct Health Care 15(1): 28-34

6. Torrance Stephens, Ronald Braithwaite, Corey Tiggs (2004) Correlates of Inmates' Self-Reported HIV/AIDS Risk Behaviors, Prior Incarceration, and Marijuana Use. The American journal of drug and alcohol abuse 30(2): 287-298.

7. Torrance Stephens, Ronald Braithwaite (2014) Correlates of sexua outcome expectations and risk of sexually transmitted infections (STIs) among male inmates in the United States. International Journa of Medicine and Medical Sciences 6(3): 92-96.

8. Torrance T Stephens, Ngozi Ogbuawa, Ronald Braithwaite (2007) Demographic profile of inhalant, amphetamine, ecstasy, and heroin use among prerelease male inmates in Georgia. The journal of men's health \& gender 4(1): 74-80.

9. Ronald L Braithwaite, Theodore M Hammett, Robert M Mayberry (1996) Prisons and AIDS: A public health challenge. Jossey-Bass Publishers, San Francisco, USA.

10. Centers for Disease Control and Prevention (CDC) (2006) HIV transmission among male inmates in a state prison system- Georgia, 1992-2005. MMWR 55(15): 421.

11. Smyth BP, Barry J, Keenan E (2001) Syringe borrowing persists in Dublin despite harm reduction interventions. Addiction 96(5): 717 727.

12. Braithwaite R, Robillard A, Woodring T, Stephens T, Arriola KJ (2001) Tattooing and body piercing among adolescent detainees: relationship to alcohol and other drug use. J Subst Abuse 13(1): 5-16.

13. Harding T (1995) HIV infection in prisons. What about the WHO guidelines?. BMJ: British Medical Journal 310(6989): 1265.

14. Novick LF, Penna RD, Schwartz MS, Remmlinger E, Loewenstein R (1977). Health status of the New York City prison population. Med Care 15(3): 205-216.

15. Freudenberg N (2001) Jails, prisons, and the health of urban populations: a review of the impact of the correctional system on community health. J Urban Health 78(2): 214-235.

16. Johnson R (2002) Hard time: Understanding and reforming the prison. Wadsworth, Belmont, CA, USA.

17. Kenneth Adams (1992) Adjusting to prison life. Crime and justice 16 : 275-359.

18. Bonhomme Jean, Stephens Torrance, and Braithwaite Ronald (2006) African-American males in the United States prison system: impact on family and community. The Journal of Men's Health and Gender 3(3): 223-226.

19. Shelley Johnson Listwan, Francis T Cull, Edward J Latess (2006). How to prevent prisoners re-entry programs from failing: Insights from evidence-based corrections. Fed Probation 70: 19-25.

20. Bandura A, Walters RH (1977) Social learning theory.

21. Bandura A (1986) Social foundations of thought and action: A social cognitive theory. Prentice-Hall, New York, USA.

22. Bandura A (1997) Self-efficacy: The exercise of control. Macmillan.

23. Donovan JE, Jessor R (1985) Structure of problem behavior in adolescence and young adulthood. J Consult Clin Psychol 53(6): 890.

24. Jessor R (1991) Risk behavior in adolescence: A psychosocial framework for understanding and action. J Adolesc Health 12(8): $597-$ 605.

25. Torrance T Stephens, Ronald Braithwaite, Alyssa Robillard, Ramona Finnie, Sha Juan Colbert (2002) A community-based approach to eliminating racial and health disparities among incarcerated populations: the HIV example for inmates returning to the community. Health Promotion Practice 3(2): 255-263.

26. John H Tyler, Jeffrey R Kling (2006) Prison-based education and reentry into the mainstream labor market (No. w12114). National Bureau of Economic Research.

27. Draine J, Wolff N, Jacoby JE, Hartwell S, Duclos C (2005) Understanding community re-entry of former prisoners with mental illness: a conceptual model to guide new research. Behav Sci Law 23(5): 689707.

28. Wohl DA, Scheyett A, Golin CE, White B, Matuszewski J (2011) Intensive case management before and after prison release is no more effective than comprehensive pre-release discharge planning in linking HIV-infected prisoners to care: a randomized trial. AIDS and Behavior 15(2): 356-364.

29. Stephens T, McGee W, Braithwaite RL (2007) Age-based correlates of substance misuse among convicted felons in Georgia. Am J Drug Alcohol Abuse 33(6): 885-892.

30. Stephan JJ (1999) State prison expenditures, 1996. US Department of Justice, Office of Justice Programs, Bureau of Justice Statistics.

31. James Austin, Marino A Bruce, Leo Carroll, Patricia L McCall, Stephen C Richards (2001) The use of incarceration in the United States. Critical Criminology 10(1): 17-41.

32. Christopher T Lowenkamp, Edward J Latessa (2004) Understanding the risk principle: How and why correctional interventions can harm low-risk offenders. Topics in community corrections 3-8.

33. Mark W Lipsey (2009) The primary factors that characterize effective interventions with juvenile offenders: A meta-analytic overview. Victims and offenders 4(2): 124-147.

34.Hung-En Sung (2003) Differential impact of deterrence vs. rehabilitation as drug interventions on recidivism after 36 months. Journal of Offender Rehabilitation 37(3-4): 95-108.

35. Braithwaite RL, Stephens TT, Treadwell HM, Braithwaite K, Conerly $\mathrm{R}$ (2005) Short-term impact of an HIV risk reduction intervention for soon-to-be released inmates in Georgia. J Health Care Poor Underserved 16(4): 130-139. 
(C) This work is licensed under Creative
Your next submission with Juniper Publishers will reach you the below assets

- Quality Editorial service

- Swift Peer Review

- Reprints availability

- E-prints Service

- Manuscript Podcast for convenient understanding

- Global attainment for your research

- Manuscript accessibility in different formats

( Pdf, E-pub, Full Text, Audio)

- Unceasing customer service

Track the below URL for one-step submission https://juniperpublishers.com/online-submission.php 